\title{
Tumor Necrosis Factor Alpha (Tnf- $\alpha)$ and Creatinine Levels in Patients at Risk of Metabolic Syndrome with Standard Therapy Combined with Black Cumin Seed Oil
}

\author{
$1^{\text {st }}$ Annis Rahmawaty \\ Pharmacology Department \\ Stikes Cendekia Utama Kudus, \\ Indonesia Pharmacology and Clinical \\ Pharmacy Department \\ Indonesia \\ annis.rahmawaty@yahoo.com \\ $4^{\text {th }}$ Titis Indri Wahyuni \\ Noncommunicable disease Department, \\ Jetis I Public Health Center \\ Bantul, Yogyakarta
}

\author{
$2^{\text {nd }}$ Akrom \\ Pharmacy Faculty \\ Universitas Ahmad Dahlan \\ Ahmad Dahlan Drug Information and \\ Crisis Center Yogyakarta \\ Indonesia \\ $5^{\text {th }}$ Dian Kumalasari \\ Pharmacology and Clinical Pharmacy \\ Department, Pharmacy Faculty, \\ Universitas Ahmad Dahlan \\ Yogyakarta, Indonesia
}

\author{
$3^{\text {rd }}$ Endang Darmawan \\ Pharmacology and Clinical Pharmacy \\ Department, Pharmacy Faculty, \\ Universitas Ahmad Dahlan \\ Yogyakarta, Indonesia \\ $6^{\text {th }}$ Adnan \\ Pharmacy Faculty \\ Universitas Ahmad Dahlan \\ Ahmad Dahlan Drug Information and \\ Crisis Center Yogyakarta \\ Indonesia
}

\begin{abstract}
Oxidative stress in metabolic syndrome (MS) results in vascular endothelial damage, generates inflammatory reactions, and increases the risk of impaired kidney function. Black cumin seed oil (BCSO) is thought to be able to improve the immune response and protect damage to the kidneys. The purpose of this study was to determine the effect of BCSO on TNF- $\alpha$ and creatinine levels in patients at risk of metabolic syndrome with standard therapy at the Jetis I Public health center (PHC). This study uses stored biological material (BM) of patients at risk of outpatient metabolic syndrome in Jetis I PHC, Bantul, for the period July 2017 to July 2018. Researchers used 61 blood specimens of patients at risk of MS, 30 of patients at risk of MS with a combination of standard therapy +BCSO, and 31 patients at risk of MS with standard + placebo combination therapy. The administration of BCSO has been done for 20 days. On the 21st day, a blood sample was taken. Blood creatinine levels were measured by the Jaffe method. TNF- $\alpha$ levels were determined by the enzyme-linked immunosorbent assay (ELISA) method in the Clinical Pathology Laboratory of the Faculty of Medicine UGM. Differences in TNF- $\alpha$ levels and creatinine levels between groups were analyzed using independent samples $t$ test $(95 \%$ confidence level). TNF- $\alpha$ levels did not differ between the two groups $(p>0.05)$. The TNF- $\alpha$ levels of the BCSO group were $101.43 \pm 22.89 \mathrm{nmol} / \mathrm{ml}$, and the placebo group $106.73 \pm 30.03 \mathrm{nmol} / \mathrm{ml}$. There was no statistically significant difference in creatinine levels between the two groups $(p<0.05)$, but it was clinically significant. The creatinine content of the BCSO group was $1.16 \pm 0.19 \mathrm{mg} / \mathrm{ml}$, and the placebo group was $1.35 \pm 0.32 \mathrm{mg} / \mathrm{ml}$ with a $p$ value> 0.05 , but it was clinically significant. Based on the results of this study, it can be concluded that the administration of BCSO additional therapy has no effect on TNF- $\alpha$ levels but
\end{abstract}

has an impact on creatinine levels in patients at risk of metabolic syndrome in Jetis I primary care center, Bantul Yogyakarta.

Keywords- Tumor Necrosis Factor Alpha (Tnf-a), Creatinine Levels, Metabolic Syndrome

\section{INTRODUCTION}

Metabolic syndrome is a severe public health problem in Indonesia. Metabolic syndrome (MS) increases the risk of cardiovascular disease and type 2 diabetes mellitus. In metabolic syndrome, there is an increased risk of insulin resistance, dyslipidemia, endothelial dysfunction, genetic susceptibility, and increased blood pressure [1]. Chronic kidney events, diabetes mellitus, stroke, and heart attacks are more common in metabolic syndrome patients[2][3]. Studies in the United States show that hypertension sufferers are twice as likely to develop type one diabetes mellitus and type 2 diabetes mellitus [4]. The prevalence of the cardiovascular disease in rural Indonesia is $19.5 \%$, while in urban areas, it is $23.4 \%$. The incidence of hypertension in rural areas of Indonesia is quite high (34.9\%), as well as diabetes mellitus $(2.7 \%)$. Based on the results of primary health research [4], the prevalence of LDL abnormalities in populations aged over 15 years in rural areas of Indonesia is $60.7 \%$, and HDL abnormalities are $24.4 \%$. Based on demographic characteristics, it is known that the prevalence of metabolic syndrome in Indonesia is higher in women (40.2\%) than men (29\%) [5]. The prevalence of metabolic syndrome patients aged 17-73 years was higher in women $23.2 \%$ than in men $18.4 \%$. The prevalence of metabolic 
syndrome in Indonesia continues to increase despite the availability of standard therapy for each metabolic syndrome patient in a public health center (PHC). New strategies for handling metabolic syndrome in the community should be pursued[6].

Increased reactive oxygen superfamily (ROS) in metabolic syndrome can cause damage to blood vessel endothelium and cause inflammatory reactions [2][7]. Tumor necrosis factor-alpha $(\mathrm{TNF}-\alpha)$ is a cytokine that is involved in the systemic inflammatory response in adipose tissue, endothelial dysfunction, and is associated with insulin resistance, obesity, and diabetes [8]. Tumor necrosis factor-alpha $(\mathrm{TNF}-\alpha)$ is a type of cytokine produced by activated mononuclear phagocytes and stimulates endothelium to express aggregation molecules. Tumor necrosis factor-alpha (TNF- $\alpha$ ) will be secreted by macrophages then infiltrated into adipose tissue and lipocytes. Tumor necrosis factor-alpha (TNF- $\alpha$ ) plays a role in the pathogenesis of metabolic syndrome, insulin resistance, and atherogenesis[9][10][11].

Hypertension, hyperglycemia, and dyslipidemia are the main risk factors for chronic kidney disease in Indonesia, besides smoking and infection. High levels of urea and creatinine in the blood due to decreased kidney function are more common in patients with DM and hypertension[12]. Indicators of kidney action can be known from the ability of glomerular filtration rate (GFR) in filtering nutrients and drugs. Patients with diabetes mellitus who have kidney damage will increase creatinine levels. It has been proven epidemiologically that DM patients have a higher risk of impaired kidney function despite receiving standard therapy [3][12][13].

The content of BCSO has been proven to have effects as antilipidemic, antihyperglycemic, antihypertensive, antioxidant, and immunomodulatory[2][14]. The cytoprotective effect of BCSO has been demonstrated through antioxidant and immunomodulatory activities [15]. The anti-inflammatory and proapoptotic effects of BCSO have been demonstrated in vivo laboratories [16]. The expression of the p53 gene in pancreatic SD mice alloxaninduced was higher in the BCSO group when compared to the control group [17]. BCSO has been shown to have antineoplastic effects on pancreatic ductal adenocarcinoma (PDA) cells. The antineoplastic effect on BCSO is known from gene activation, which shows the presence of proapoptotic activation significantly reduces the synthesis of pancreatic ductal adenocarcinoma (PDA) monocyte chemoattractant protein-1 (MCP-1), TNF- $\alpha$, interleukin (IL) $-1 \mathrm{~b}$ and Cox-2 (Cox-2 (C)) synthesis cells. [18][19]. The administration of BCSO has been proven to improve the healing process of patients. Phase I clinical trial results have been shown that the administration of BCSO for 21 days to 36 healthy volunteers does not affect kidney function [20]. Nigella sativa L. provides a protective effect and useful for preventing kidney failure [21], antidiabetogenic [22], antioxidant [2], chemoprevention [23], and immunomodulatory agent [24].BCSO preparations are thought to affect TNF- $\alpha$ levels and creatinine levels in patients at risk of MS with standard therapy.

\section{MATERIAL AND METHOD}

\section{A. Design}

This analytic observational study with a cohort design aims to determine the effectiveness of BCSO administration to TNF- $\alpha$ levels, and creatinine in patients at risk of metabolic syndrome at Jetis I Public Health Center (PHC), Bantul, Yogyakarta. The study was conducted in July 2017-July 2018 [7].

Blood samples came from 61 outpatient SM at-risk patients in the Bantul Jetis I Public Health Center. Blood samples came from $61 \mathrm{SM}$ at-risk patients from a previous study conducted by Akrom et al., at the Jetis 1 PHC, Bantul[7]. Blood samples have been taken by trained personnel by protocols that have been approved by the Ahmad Dahlan University ethics committee. Since the collection is used for examination, blood samples are stored at freezing temperatures in the UGM Clinical Pathology Laboratory. Before being used, an investigation has been carried out and confirmed that the blood sample is fit to be tested.

The tools used in this study were 1) form to record patient demographic data, 2) medical records to determine the patient's disease status, 3) digital blood pressure measuring devices to measure patient's blood pressure, 4) weight scales and height gauges to identify the body mass index (BMI) ) patients, 5) ELISA to measure TNF- $\alpha$ levels, 6) autoanalyzer photometer to measure creatinine levels, 7) Statistical Package software for the Social Sciences (SPSS) version 16 to analyze the data.

\section{B. Procedure}

We took: age, sex, medical history, weight, height, body mass index, and blood pressure data from the patient's medical record database. Measurement of baseline data for patients with metabolic syndrome included body mass index (BMI), high-density lipoprotein (HDL), blood sugar, cholesterol, triglycerides, and blood pressure. Blood sampling from the cubital vein was carried out on the $21 \mathrm{st}$ day of the study. Subjects received treatment for 20 days. The BCSO group received $3 \mathrm{ml} /$ day BCSO combined with standard therapy for 20 days. The placebo group was given a placebo in combination with standard treatment for 20 days.

\section{Analysis of TNF- $\alpha$ levels by the ELISA Method}

The examination of TNF- $\alpha$ levels uses an Enzymelinked immunosorbent assay (ELISA) tool. The reagent used was TNF- $\alpha$ (Fine Test, China). Anti TNF- $\alpha$ antibodies are first coated into 96 plate wells. Then biotin-conjugated anti-TNF- $\alpha$ antibodies are used as antibody detectors. Standards, test samples, and detection of biotin-conjugated antibodies are added to the plate. Then wash it with washing buffer. HRP-Streptavidin is added, and the unattached conjugate is cleaned with a washing buffer. Substrate 3,3 ', 5,5'-tetramethylbenzidine (TMB) is used to visualize the enzymatic reaction of horseradish peroxidase (HRP). TMB is catalyzed by HRP to produce a blue product that turns yellow after adding the stop solution. The yellow density is proportional to the number of TNF- $\alpha$ samples captured on the plate. Then read the absorbance at $450 \mathrm{~nm}$ lambda on a microplate reader, and then the TNF- $\alpha$ concentration can be calculated. The color of the solution in the well from blue to 
yellow, the results are read using an ELISA reader. Results are expressed in pg / $\mathrm{mL}$ (picogram / millilitre).

D. Creatinine Level Analysis

Measurement of serum creatinine levels using the Jaffe method of blood samples collected in a $1.5 \mathrm{ml}$ microtube given heparin, centrifuged at a speed of $8000 \mathrm{rpm}$ for 10 minutes. The test material is taken using a micropipette and put into a test tube. The complex reactions formed are yellow with picric acid in an alkaline atmosphere. The serum creatinine was read by visible spectrophotometry at a wavelength of $492 \mathrm{~nm}$ with $37^{\circ} \mathrm{C}$. Data in the form of absorbance, recorded and calculated into blood creatinine levels in $\mathrm{mg} / \mathrm{dl}$.

\section{E. Data analysis}

Demographic data (gender, age, occupation, education, and marital status) were analyzed using frequency tests to obtain a percentage result. Analysis of the normality test on TNF- $\alpha$, urea, and creatinine levels was carried out independent t-test for normally distributed data to identify the effectiveness of the administration of BCSO associated with TNF- $\alpha$, urea and creatinine levels in patients at risk of metabolic syndrome.

\section{RESULTS AND DISCUSSION}

A. Demographic characteristics of respondents

The demographic characteristics of the subjects are presented in Table I.

TABLE I. DEMOGRAPHIC CHARACTERISTICS OF PATIENTS AT RISK OF MS WITH BCSO AND PLACEBO IN JETIS I PHC, BANTUL.

\begin{tabular}{|c|c|c|c|c|c|c|}
\hline \multirow{2}{*}{ Status } & \multicolumn{2}{|c|}{ BCSO group } & \multicolumn{2}{|c|}{ Placebo group } & \multicolumn{2}{|c|}{ Total } \\
\hline & $\mathbf{n}$ & $\%$ & $\mathbf{n}$ & $\%$ & total & $\%$ \\
\hline Subjek (N) & 30 & 49,2 & 31 & 50,8 & 61 & 100 \\
\hline \multicolumn{7}{|l|}{ Sex } \\
\hline Male & 7 & 23,3 & 7 & 22,6 & 14 & 22,9 \\
\hline Female & 23 & 76,7 & 24 & 77,4 & 47 & 77,1 \\
\hline \multicolumn{7}{|l|}{ Age } \\
\hline $18-40$ year & 0 & 0,0 & 3 & 9,6 & 3 & 4,9 \\
\hline $41-60$ year & 21 & 70,0 & 14 & 45,2 & 35 & 57,4 \\
\hline$>61$ year & 9 & 30,0 & 14 & 45,2 & 23 & 37,7 \\
\hline \multicolumn{7}{|l|}{ Job } \\
\hline $\begin{array}{l}\text { government } \\
\text { employees }\end{array}$ & 3 & 10,0 & 1 & 3,2 & 4 & 6,6 \\
\hline Enterpreneur & 4 & 13,3 & 4 & 12,9 & 8 & 13,2 \\
\hline Farmer & 3 & 10,0 & 4 & 12,9 & 7 & 11,5 \\
\hline Privat job & 2 & 6,7 & 1 & 3,2 & 3 & 4,9 \\
\hline Labor & 4 & 13,3 & 5 & 16,1 & 9 & 14,6 \\
\hline Fisherman & 4 & 13,3 & 1 & 13,2 & 5 & 8,2 \\
\hline No Job & 10 & 33,3 & 15 & 48,4 & 25 & 41,0 \\
\hline \multicolumn{7}{|l|}{ Education } \\
\hline Elementary education & 17 & 56,7 & 17 & 54,9 & 34 & 55,7 \\
\hline$\geq$ hight school & 10 & 33,3 & 11 & 35,5 & 21 & 34,4 \\
\hline No education & 3 & 10,0 & 3 & 9,7 & 6 & 9,9 \\
\hline \multicolumn{7}{|l|}{ Marital status } \\
\hline Single & 0 & 0,0 & 1 & 3,2 & 1 & 1,7 \\
\hline Marriage & 30 & 100 & 30 & 96,8 & 60 & 98,3 \\
\hline
\end{tabular}

Table I illustrates the demographic characteristics of the patient (sex, age, occupation, education, and marital status). The number of female patients in this study was more than male patients $(77.1 \% ; 22.9 \%)$. Research on the prevalence of metabolic syndrome in the elderly population of China between 2001 and 2010 involving 2,102 participants (848 men, 1,254 women) showed a higher incidence of $59.7 \%$ in women compared to $40.3 \%$ in men [25]. Characteristics of research subjects at risk of metabolic syndrome patients based on age known that metabolic syndrome is more experienced in the age group 41-60 years (57.4\%), women aged 55-64 years at risk of developing metabolic syndrome due to a decrease in some organ functions including decreased function pancreatic endocrine to produce insulin, reduced muscle mass and decreased mitochondrial activity in muscle cells[26].
The result of the prevalence of metabolic syndrome in the occupational group was higher in the non-working group $(41 \%)$, in line with a previous study that metabolic syndrome occurs in almost one-third of people who do not work and do not have much activity [26]. People with unhealthy lifestyles show a higher health hazard for the occurrence of metabolic syndrome[27]. Unemployment People have psychology stress because stress may be associated with obesity, lack of exercise, and trigger weight gain[28].

Metabolic syndrome is seen from marital status in this study as much as $98.3 \%$ more risk of experiencing metabolic syndrome compared with unmarried [4][29]. The development of the cardiovascular disease can be related to one's marital status because it is due to the influence of the quality of the marriage undertaken with metabolic factors, differences in metabolic state of the body and types of fat 
substitution in different tissues is one theory about the increased incidence of metabolic syndrome [30].
B. Clinical Conditions for Patients at Risk for $M S$

The clinical characteristics of MS patients at the Jetis I PHC, Bantul, are presented in Table II.

TABLE II. CLINICAL CHARACTERISTICS OF PATIENTS AT RISK OF MS BASED ON THE TREATMENT GROUP IN JETIS I PHC, BANTUL

\begin{tabular}{|l|c|c|c|}
\hline & \multicolumn{2}{|c|}{ Mean \pm SD } & P-value \\
\hline Clinical Characteristic & $\begin{array}{c}\text { BCSO Group } \\
(\mathbf{n}=\mathbf{3 0})\end{array}$ & $\begin{array}{c}\text { Placebo Group } \\
(\mathbf{n}=\mathbf{3 1})\end{array}$ & \\
\hline $\mathbf{S B P} \pm \mathbf{S D}(\mathbf{m m H g})$ & $140,83 \pm 17,02$ & $139,00 \pm 13,24$ & 0,92 \\
\hline $\mathbf{D B P} \pm \mathbf{S D}(\mathbf{m m H g})$ & $80,77 \pm 10,08$ & $75,39 \pm 13,24$ & 0,33 \\
\hline $\mathbf{B M I} \pm \mathbf{S D}(\mathbf{k g} / \mathbf{m} \mathbf{2})$ & $25,39 \pm 3,80$ & $24,57 \pm 4,43$ & 0,63 \\
\hline $\mathbf{C h o l} \pm \mathbf{S D}(\mathbf{m g} / \mathbf{d L})$ & $187,50 \pm 52,28$ & $180,12 \pm 47,78$ & 0,20 \\
\hline $\mathbf{B G} \pm \mathbf{S D}(\mathbf{m g} / \mathbf{d L})$ & $187,40 \pm 90,00$ & $256,29 \pm 76,37$ & 0,69 \\
\hline $\mathbf{T G} \pm \mathbf{S D}(\mathbf{m g} / \mathbf{d L})$ & $151,10 \pm 75,85$ & $186,68 \pm 117,49$ & 0,38 \\
\hline HDL $\pm \mathbf{S D}(\mathbf{m g} / \mathbf{d L})$ & $45,56 \pm 6,42$ & $44,32 \pm 5,49$ & 0,15 \\
\hline
\end{tabular}

$\mathrm{Nb}$ :

$\mathrm{SBP}=$ systolic blood pressure;

$\mathrm{DBP}=$ diastolic blood pressure;

BMI=body mass index;

Chol=cholesterol;

BG=blood glucose;

TG=triglyceride

The mean value of the analysis of clinical characteristics data in table 2 consisted of systolic blood pressure ( $\mathrm{p}=$ $0.92)$, diastolic blood pressure $(\mathrm{p}=0.33)$ BMI $(\mathrm{p}=0.63)$ cholesterol $(\mathrm{p}=0.20)$ serum blood sugar $(\mathrm{p}=0.69)$, triglycerides $(p=0.38)$ and HDL $(p=0.15)$. Subjects at risk of metabolic syndrome who were given a dose of $3 \mathrm{~mL} /$ day and placebo there were no significant differences between the two ( $p>0.05)$.

The data of this study stated that the mean systolic blood pressure, mean diastolic blood pressure, body mass index, serum blood glucose level, and high-density lipoprotein in the BCSO group have not yet reached the target of therapy. $\mathrm{BCSO}$ is not effective in reducing blood pressure, blood glucose levels, BMI, and increasing HDL levels; the results of this study are different from previous studies. The duration of the study is thought to be one of the ineffective factors in administering BCSO in this study. BCSO administration for 21 days was not adequate to give the expected effect[31].

Patients at risk of metabolic syndrome should have a specific therapeutic target. The goal therapy of systolic blood pressure (TDS) is $<140 \mathrm{mmHg}$, and diastolic blood pressure (TDD) is $<85 \mathrm{mmHg}$ [32]. The goal of body mass index (BMI) therapy is $<30 \mathrm{~kg} / \mathrm{m} 2$, cholesterol (Chol) level is $<200 \mathrm{mg} / \mathrm{dL}$. The target of blood glucose (BG) level should be $<140 \mathrm{mg} / \mathrm{dL}$. The goal therapy of triglycerides level is $<200 \mathrm{mg} / \mathrm{dl}$ and and $<40 \mathrm{mg} / \mathrm{dL}$ for high-density lipoprotein (HDL) [33].

\section{C. $T N F-\alpha$, and creatinine levels}

The results of an examination of TNF- $\alpha$ and creatinine levels in patients at risk of metabolic syndrome who received additional $\mathrm{BCSO}$ doses of $3 \mathrm{~mL} /$ day and placebo for 20 days were analyzed using the Independent-T test as shown in table III.

TABLE III. TNF-A (IN PMOL/ML) AND CREATININE LEVELS (MG/DL) WERE BASED ON THE TREATMENT GROUP OF AT-RISK PATIENTS IN JETIS I PHC, BANTUL

\begin{tabular}{|l|l|l|l|}
\hline \multicolumn{1}{|c|}{ Variable } & \multicolumn{1}{|c|}{ Status } & Mean \pm SD & \multicolumn{1}{|c|}{$\boldsymbol{p}$} \\
\hline TNF- $\boldsymbol{\alpha}$ & Dosis $3 \mathrm{~mL} / \mathrm{hari}$ & $101,43 \pm 22,89$ & \\
& & & \\
& & & \\
\cline { 2 - 3 } & Placebo & $106,73 \pm 30,03$ & \\
\hline Creatinin & Dosis 3mL/hari & $1,16 \pm 0,19$ & \multirow{2}{*}{0,077} \\
& & & \\
& & & \\
\cline { 2 - 3 } & Placebo & $1,35 \pm 0,32$ & \\
\hline
\end{tabular}

Table III shows that the Independent-test on the TNF- $\alpha$ variable obtained $p$ value $>0.05$. A $p$-value higher than 0.05 indicates that in the BCSO group, the dose was $3 \mathrm{~mL} /$ day, and in the placebo group, there was no significant difference in TNF- $\alpha(p=0.857)$. The data from this study are consistent with the clinical output data of the BCSO group in Table II. The duration of the administration of
BCSO is thought to be related to the difference in TNF-a levels of the BCSO group with the placebo group.

BCSO adjunctive therapy in routine therapy of DM patients in Jetis I PHC was proven effective in reducing creatinine levels, both statistically and clinically ( $p<0.05)$. The results of the study reinforce the results of previous 
studies, which showed that the administration of BCSO is nephroprotective both in vivo and clinically[21].

Metabolic syndrome patients have altered fat conditions, and adiposity cells will maintain energy balance by releasing tumor necrosis factor- $\alpha(\mathrm{TNF}-\alpha)$ and monocyte chemotactic protein-1 (MCP-1). TNF- $\alpha$ can trigger the formation of creative protein (CRP) in the liver, which, if produced continuously, can worsen inflammatory conditions; also, obesity is accompanied by an increase in fat metabolism, which will cause increased ROS production and result in oxidative stress. Increased oxidative stress causes dysregulation of adipose tissue and is the beginning of the pathophysiology of the metabolic syndrome [1] [12]. Elevated levels of TNF- $\alpha$ in diabetics can be seen from the state of hyperglycemia that occurs due to an increase in oxidative stress that can cause inflammation. The state of hyperglycemia can affect the wound healing process of diabetics due to decreased fibroblast cell proliferation[30] [33].

Hypertension, diabetes, and high triglycerides are risk factors that can cause proteinuria and kidney disease. Increases in blood pressure, fasting plasma glucose levels, and individual triglycerides are part of a component of the metabolic syndrome and also a significant risk factor for increased serum creatinine and the occurrence of chronic kidney disease (CKD) [34]. Increasing the success of achieving therapeutic targets for blood glucose levels in DM and blood pressure in hypertension is a real effort to reduce the incidence of $\mathrm{CKD}[12][35]$.

\section{CONCLUSION}

Based on the results of this study, it can be concluded that the administration of BCSO additional therapy dose of $3 \mathrm{~mL} /$ day with control/placebo has the same effect on TNF$\alpha$ and creatinine levels in patients at risk of metabolic syndrome at Jetis I PHC, Bantul, Yogyakarta.

\section{ACKNOWLEDGMENT}

To Jetis 1 Public Health Center, Bantul, Yogyakarta leaders, and staff, many thanks for your support and giving the author a chance for the research.

\section{REFERENCES}

[1] E. McCracken, M. Monaghan, and S. Sreenivasan, "Pathophysiology of the metabolic syndrome," Clin. Dermatol., vol. 36, no. 1, pp. 14-20, 2018

[2] T. Hidayati, A. Pramono, I. M. Jenie, and M. H. Soesatyo, "Evaluation of black cumin seeds hexane extract as reactive oxygen intermediates (ROI) and phagocytic activity modulator in DMBA inducedrats," Biomed. Res., vol. 28, no. 4, pp. 1755$1760,2017$.

[3] A. Akrom, E. Darmawan, and N. Maulida, "Factors relate to the hypercreatininemia event of patients at the risk of metabolic syndrome in Jetis I public health center," Pharmaciana, vol. 7, no. 2, p. 205, 2017.

[4] H. S. N. F. I. Titiek, "normal fasting blood sugar levels and medication adherence improve the quality of life of type 2 diabetes mellitus patients in primary health facilities," Asian $J$. Pharm. Clin., vol. 11, no. 11, 2018.

[5] M. Lukman, K. Ibrahim, D. I. Yani, S. P. Sari, and N. Juniarti, "Exploring strategies to improve the performance of community health volunteers for tuberculosis care and prevention: A qualitative study," Int. J. Community Based Nurs. Midwifery, vol. 7, no. 4, pp. 270-278, 2019.

[6] H. Idris, H. Hasyim, and F. Utama, "Analysis of Diabetes Mellitus Determinants in Indonesia: A Study from the Indonesian
Basic Health Research 2013," Acta Med. Indones., vol. 49, no. 4, pp. 291-298, 2017.

[7] P. N. R. Rachman, Akrom, and E. Darmawan, "The efficacy of black cumin seed (Nigella sativa) oil and hypoglycemic drug combination to reduce $\mathrm{HbA} 1 \mathrm{c}$ level in patients with metabolic syndrome risk," in IOP Conference Series: Materials Science and Engineering, 2017, vol. 259, no. 1.

[8] U. A. Dahlan, M. Marzuqoh, and U. A. Dahlan, "Clinical Pharmacoepidemiology Study of Antihypertensive and Antidiabetes Mellitus Drug in DM-Hypertensive Outpatient in a Private Hospital," vol. 18, no. July 2017, pp. 48-56, 2019.

[9] G. K. Kolluru, S. C. Bir, and C. G. Kevil, "Endothelial dysfunction and diabetes: Effects on angiogenesis, vascular remodeling, and wound healing," Int. J. Vasc. Med., vol. 2012, no. Figure 1, 2012.

[10] F. C. Chang et al., "Angiopoietin-2 Is Associated with Albuminuria and Microinflammation in Chronic Kidney Disease," PLoS One, vol. 8, no. 3, pp. 4-9, 2013.

[11] J. Akter et al., "Endothelium-independent and calcium channeldependent relaxation of the porcine cerebral artery by different species and strains of turmeric," J. Tradit. Complement. Med., vol. 9, no. 4, pp. 297-303, 2019.

[12] A. Akrom and W. Anggitasari, "Adherence and quality of life among diabetic patients with hypertension," vol. 8, no. 1, pp. 1419, 2019.

[13] E. I. Omodanisi, Y. G. Aboua, O. O. Oguntibeju, and R. M. Lamuela-Raventós, "Assessment of the anti-hyperglycaemic, anti-inflammatory and antioxidant activities of the methanol extract of moringa oleifera in diabetes-induced nephrotoxic male wistar rats," Molecules, vol. 22, no. 4, pp. 1-16, 2017.

[14] T. Hidayati, "Black Cumin Seeds Extract Increase Lymphocyte Activity in IFN- $\gamma$ Secretion in Sprague Dawley Rat ( SD ) Induced by Dimethylbenzantracene," no. October, pp. 140-148, 2019.

[15] A. H. Mahmoud YK, "Cancer: Thymoquinone antioxidant/prooxidant effect as potential anticancer remedy," Biomed Pharmacother, vol. 3, no. 115, p. 108783, 2019.

[16] Akrom and Mustofa, "Black cumin seed oil increases phagocytic activity and secretion of IL-12 by macrophages.," Biomed. Res., vol. 28 , no. 12, 2017.

[17] A. Akrom, R. Nurfadjrin, E. Darmawan, and T. Hidayati, "Black Cumin Seed Oil Antidiabetogenic by Increasing Pancreatic P53 Expression," Int. J. Public Heal. Sci., vol. 7, no. 3, p. 207, 2018.

[18] M. Zhang et al., "Thymoquinone induces apoptosis in bladder cancer cell via endoplasmic reticulum stress-dependent mitochondrial pathway," Chem. Biol. Interact., vol. 292, no. February, pp. 65-75, 2018

[19] Z. M. Aljohani et al., "Evaluation of the potential beneficial effects of thymoquinone against nicotine induced toxicity," Int. J. Pharm. Clin. Res., vol. 7, no. 6, pp. 395-398, 2015.

[20] A. Akrom and E. Darmawan, "Tolerability and safety of black cumin seed oil (Bcso) administration for 20 days in healthy subjects," Biomed. Res., vol. 28, no. 9, 2017.

[21] A. Elkhateeb, I. El Khishin, O. Megahed, and F. Mazen, "Effect of Nigella sativa Linn oil on tramadol-induced hepato- and nephrotoxicity in adult male albino rats," Toxicol. Reports, vol. 2, pp. 512-519, 2015.

[22] D. R. Fajar, Akrom, and E. Darmawan, "The influence of black cumin seed oil therapy with dosage of $1.5 \mathrm{~mL} /$ day and $3 \mathrm{~mL} /$ day to interleukin-21 (IL-21) expression of the patients with metabolic syndrome risk," in IOP Conference Series: Materials Science and Engineering, 2017, vol. 259, no. 1.

[23] T. Hidayati, Akrom, Indrayanti, and Sagiran, "Chemopreventive effect of black cumin seed oil (BCSO) by increasing p53 expression in dimethylbenzanthracene (DMBA)-induced Sprague Dawley rats," Res. J. Chem. Environ., vol. 23, no. 8, 2019.

[24] T. Hidayati and A. Akrom, "Black cumin seed oil increase leucocyte and CD4Thelper number in sprague-dawley rats induced with dimethylbenzanthracene," vol. 8 , no. 2 , pp. $238-$ $245,2019$.

[25] N. Akseer et al., "Geospatial inequalities and determinants of nutritional status among women and children in Afghanistan: an observational study," Lancet Glob. Heal., vol. 6, no. 4, pp. e447e459, 2018. 
[26] J. E. Villena, "Diabetes Mellitus in Peru," Ann. Glob. Heal., vol. 81 , no. 6, pp. 765-775, 2015.

[27] H. Bergström, M. Hagströmer, J. Hagberg, and L. S. Elinder, “A multi-component universal intervention to improve diet and physical activity among adults with intellectual disabilities in community residences: A cluster randomised controlled trial," Res. Dev. Disabil., vol. 34, no. 11, pp. 3847-3857, 2013.

[28] A. J. Doherty, S. P. Jones, U. Chauhan, and J. M. E. Gibson, “An integrative review of multicomponent weight management interventions for adults with intellectual disabilities," J. Appl. Res. Intellect. Disabil., vol. 31, no. April 2017, pp. 39-51, 2018.

[29] S. O'Neill and L. O'Driscoll, "Metabolic syndrome: A closer look at the growing epidemic and its associated pathologies," Obes. Rev., vol. 16, no. 1, pp. 1-12, 2015.

[30] T. Hidayati, "Relationship of Diet with Overweight Events in Disabled Youth," vol. 18, pp. 33-36, 2019.

[31] A. Ahmad et al., "A review on therapeutic potential of Nigella sativa: A miracle herb," Asian Pac. J. Trop. Biomed., vol. 3, no. 5, pp. 337-352, 2013.

[32] M. Jane E.B. Resuch, "2019 Standards of Medical Care in Diabetes : What is New and Why," Diabetes Care ADA, 2019.

[33] J. J. Gagliardino et al., "Diabetes education and health insurance: How they affect the quality of care provided to people with type 1 diabetes in Latin America. Data from the International Diabetes Mellitus Practices Study (IDMPS)," Diabetes Res. Clin. Pract., vol. 147, pp. 47-54, 2019.

[34] D. W. Ploth et al., "Prevalence of CKD, Diabetes, and Hypertension in Rural Tanzania," Kidney Int. Reports, vol. 3, no. 4, pp. 905-915, 2018.

[35] G. Z. Saputri, A. Akrom, and E. Darmawan, "Improving Outpatient's Quality of Life through Patient Adherence of Antihypertensive Therapy Using 'Mobile Phone (SMS) and Brief Counseling-5A' in Polyclinic of Internal Medicine at PKU Muhammadiyah Bantul Hospital, Yogyakarta," Indones. J. Clin. Pharm., vol. 6, no. 2, pp. 67-77, 2017. 